\title{
Article
}

\section{Removing tar and nicotine from mainstream cigarette smoke using sepiolite-modified filter tips}

\author{
Yüksel Sarıkaya ${ }^{1}$, Naime Didem Kahya ${ }^{1}$, Abdullah Devrim Pekdemir ${ }^{2}$ and Müşerref Önal ${ }^{1 \star}$ \\ ${ }^{1}$ Ankara University, Faculty of Science, Department of Chemistry, 06100 Tandoğan, Ankara, Turkey and ${ }^{2}$ Ankara University, Graduate School of Natural \\ and Applied Sciences, 06110 Dışkapı, Ankara, Turkey
}

\begin{abstract}
The objective of this work was to use air-dried sepiolite granules as an additive in cigarette filter tips to increase the removal yield of tar and nicotine from mainstream smoke. Granules with a mass of $95 \mathrm{mg}$ per cigarette filter and a mean particle size $(D)$ of $0.05-0.41 \mathrm{~mm}$ were used to constrain the effects of the mean particle size and mass of sepiolite in the removal process. The granules were sandwiched in common cellulose acetate filter tips. Maximum removal yields of $90 \%$ were obtained when $D \leq 0.10$ mm. Filters containing granules with a mean size of $0.10 \mathrm{~mm}$ and mass variations from 35 to $95 \mathrm{mg}$ were tested, and increasing amounts of sepiolite added led to progressively greater yields of tar and nicotine from $20 \%$ to $90 \%$. The sepiolite granules were examined using scanning electron microscopy with energy-dispersive X-ray spectroscopy, Fourier-transform infrared spectroscopy and X-ray diffraction techniques both before and after smoke experimentation. It is suggested that tar and nicotine were condensed both on the fibre clusters of the sepiolite granules and in the voids between them during the flow of the mainstream smoke.
\end{abstract}

Keywords: cigarette filter, mainstream smoke, nicotine, sepiolite, tar

(Received 12 August 2020; revised 9 February 2021; Accepted Manuscript online: 1 March 2021; Associate Editor: Lawrence Warr)

Commercial cigarettes consist of a specially prepared tobacco blend, air-permeable paper and a common filter made of cellulose acetate fibres. In addition, several substances are added to tobacco blends to impart specific desirable properties (Thielen, 2008). Cigarettes can be burned either with flame or flameless during smoking. As tobacco is a natural organic material, the smoke formed through flame burning contains mainly carbon dioxide, carbon monoxide, nitrogen oxides and water vapours. The cigarette smoke is essentially an aerosol composed of liquid droplets suspended in a mixture of these gases and water vapour. Moreover, during the smoking process, two kinds of smoke with various physicochemical properties are released. The first is mainstream smoke (MSS) inhaled by the smoker. The second is sidestream smoke (SSS) released into the environment between puffs from the flameless burning at the other end of the cigarette. The formation temperature intervals for the MSS and the SSS are $850-950^{\circ} \mathrm{C}$ and $500-650^{\circ} \mathrm{C}$, respectively (Thielen, 2008).

The temperature of the MSS decreases gradually along the direction towards the smoking end of the cigarette. Numerous toxic compounds found in the MSS originate from burning, pyrolysis and pyrosynthesis between the two ends of the cigarette (Rustemeier et al., 2002; Counts et al., 2005; Panday \& Kim, 2010). The condensed residue in the filter materials is a mixture of tar, which contains various toxic polycyclic aromatic hydrocarbons, and alkaloids, mainly nicotine.

\footnotetext{
*Email: onal@science.ankara.edu.tr
}

Cite this article: Sarıkaya Y, Kahya ND, Pekdemir AD, Önal M (2020). Removing tar and nicotine from mainstream cigarette smoke using sepiolite-modified filter tips. Clay Minerals 55, 375-382. https://doi.org/10.1180/clm.2021.7
The International Union of Pure and Applied Chemistry (IUPAC) name for nicotine $\left(\mathrm{C}_{10} \mathrm{H}_{14} \mathrm{~N}_{2}\right)$ is 3-(1-methyl-2pyrrolidinyl) pyridine and its structural formula is as follows:

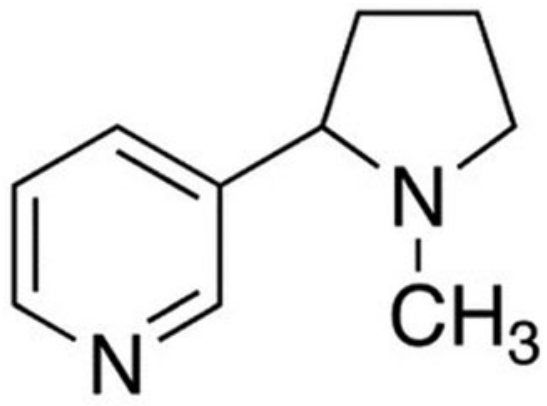

The solubility of nicotine in water and organic solvents varies depending on the $\mathrm{pH}$ value of the mixture. Nicotine has a standard boiling temperature of $245.5^{\circ} \mathrm{C}$ and dissolves in water completely at room temperature. However, the mixture of water and nicotine releases emulsions at a temperature range of $60-210^{\circ} \mathrm{C}$ depending on the composition at atmospheric pressure. By contrast, the large organic compounds in tar are insoluble in water.

Some of the toxic compounds in the MSS are removed using a filter tip, which facilitates several physicochemical processes such as condensation, adsorption, absorption and various chemical reactions (Smith et al., 1997; Ködderitzsch et al., 2005; Purkis et al., 2011). However, most of the common cigarette filter tips alone do not fully remove the compounds that are harmful to human health (Kim et al., 2016; Pinto et al., 2017). To increase 
the efficiency of filters, several materials such as silk fibres (Tian et al., 2009), alumina (Verdolotti et al., 2012), zeolite (Xu et al., 2003; Gao et al., 2009), active carbon (Coggins et al., 2008; Sasaki et al., 2008), carbon nanotubes (Chen et al., 2006), carbon nanocages (Li et al., 2011) and sepiolite (Zhang 2000) have been added to the filter tips (Lamb \& Parenski, 1984; Figlar et al., 2004). In previous studies, sepiolite granules with diameters of $\leq 100 \mu \mathrm{m}$ were admixed with cigarette paper or were distributed in the cellulose acetate filter tip (Artho et al., 1976). However, it is still unclear how important the granule size and necessary mass of the inorganic additives are for sufficient removal of tar and nicotine.

Among the porous materials used to increase the efficiency of smoke filtration, only sepiolite has a fibrous crystal structure (Moore \& Reynolds, 1997; Bergaya et al., 2006). The natural sepiolite clays typically contain carbonates such as dolomite $\left(\mathrm{CaMg}\left(\mathrm{CO}_{3}\right)_{2}\right)$, calcite $\left(\mathrm{CaCO}_{3}\right)$, magnesite $\left(\mathrm{MgCO}_{3}\right)$ and other impurities depending on the deposit and geological origin (Inukai et al., 1994; Yener et al., 2007). It is also possible to synthesize pure sepiolite using $\mathrm{MgCl}_{2}$ and $\mathrm{SiO}_{2}$ mixtures under laboratory conditions (Abtahi, 1985). The chemical formula of pure sepiolite is $\mathrm{Si}_{12} \mathrm{O}_{30} \mathrm{Mg}_{8}(\mathrm{OH})_{4}\left(\mathrm{OH}_{2}\right)_{4} \cdot 8 \mathrm{H}_{2} \mathrm{O}$ for the half-unit cell (Brauner \& Preisinger, 1959; Serna et al., 1975; Tian et al., 2019), where $(\mathrm{OH})_{4},\left(\mathrm{OH}_{2}\right)_{4}$ and $8 \mathrm{H}_{2} \mathrm{O}$ represent the structural hydroxyls (Ahlrichs et al., 1975; Y1lmaz et al., 2013), bound water (Kiyohiro \& Otsuka, 1989; Ogorodova et al., 2014) and zeolitic water (Prost, 1975; Rouquerol et al., 2014), respectively. The zeolitic water of sepiolite is removed by heating to $250^{\circ} \mathrm{C}$ (Bergaya et al. 2006; Sarıkaya et al. 2020b). Accordingly, the nanopores in air-dried sepiolite are filled with zeolitic water.

The crystal structure and nanoporosity of sepiolite can be modified easily using thermal treatments depending on the temperature conditions applied (Balc1, 1999; Frost \& Ding, 2003; Perraki \& Orfanoudaki, 2008; Wang et al., 2014). Sintering of sepiolite at higher temperatures produces new phases (Kulbicki, 1959; Göktaş et al., 1997). The kinetics and thermodynamic parameters for the thermal degradation of sepiolite at various applied temperatures have been evaluated using X-ray diffraction (XRD) and thermal analysis (Sarikaya et al., 2020a, 2020b).

Raw and modified sepiolite samples have found various applications (Galan, 1996; Murray, 1999): for example, as adsorbents (González-Santamaria et al., 2017), clarification agents (Erdoğan et al., 1996; Mirzaaghaei et al., 2017), bleaching earths (Tian et al., 2014; Laatikainen et al., 2015; Saneei et al., 2015) and catalysts (Al-Ani et al., 2018; Meşe et al., 2018). Acid activation (Çetişli \& Gedikbey, 1990; Yebra-Rodriguez et al., 2003) and other chemical modifications (Shuali et al., 1991; Fitaroni et al., 2019; Papoulis et al., 2019) have a strong effect on the physicochemical properties of sepiolite, including on its crystal structure (Özdemir \& Kıpçak, 2004), surface acidity (Bonilla et al., 1981), surface area (Jimenez-Lopez et al., 1978), nanoporosity (Rodriguez-Reinoso et al., 1981) and catalytic activity (Corma et al., 1984). The purpose of this study was to investigate the effects of mean particle size and the added mass of sepiolite granules as a filter additive for improving the removal of tar and nicotine in the MSS of cigarettes based on controlled experimentation.

\section{Material and methods}

\section{Sepiolite from Eskişehir, Turkey}

The white-coloured sepiolite, also known as pipestone, was used as an additive in cigarette filter tips. Its geological formation
Table 1. The dry screen analysis of sepiolite granules.

\begin{tabular}{lcc}
\hline$-r(\mathrm{~mm})$ & $+r(\mathrm{~mm})$ & $r(\mathrm{~mm})$ \\
\hline-0.10 & 0.00 & 0.05 \\
-0.16 & 0.00 & 0.08 \\
-0.20 & 0.00 & 0.10 \\
-0.20 & 0.10 & 0.15 \\
-0.32 & 0.20 & 0.26 \\
-0.50 & 0.20 & 0.35 \\
-0.50 & 0.32 & 0.41 \\
\hline
\end{tabular}

and mineralogical composition have been extensively investigated in previous studies (Ece \& Çoban, 1994). A number of its physicochemical properties (chemical composition, mineralogy, morphology, particle-size distribution, porosity and specific surface area) as well as the change in its crystal structure and linear shrinkage as a function of the temperature of the raw sepiolite used in this study have been examined previously (Önal et al., 2008). The chemical composition of the sepiolite in mass\% is: $\mathrm{SiO}_{2}, 55.45 ; \mathrm{MgO}, 26.53 ; \mathrm{Al}_{2} \mathrm{O}_{3}, 0.85 ; \mathrm{Fe}_{2} \mathrm{O}_{3}, 0.07 ; \mathrm{TiO}_{2}, 0.06$; $\mathrm{CaO}, 1.86 ; \mathrm{Na}_{2} \mathrm{O}, 0.06 ; \mathrm{K}_{2} \mathrm{O}, 0.08$; and loss on ignition (LOI), 14.60. The sepiolite contains 6.3 mass $\%$ dolomite and has a cation-exchange capacity (CEC) of $0.27 \mathrm{meq} \mathrm{g}^{-1}$. The internal widths of the voids in solids $<2 \mathrm{~nm}$, between 2 and $50 \mathrm{~nm}$ and $>50 \mathrm{~nm}$ are called micropores, mesopores and macropores, respectively (Rouquerol et al., 2014). In addition, the voids of interval width $<100 \mathrm{~nm}$ are defined as nanopores. Sepiolite has open intra-crystalline pores in the form of interconnected channels running parallel to the fibre length (Bergaya et al., 2006). The specific micropore, mesopore and macropore volumes for the sepiolite used are $0.16,0.21$ and $0.45 \mathrm{~cm}^{3} \mathrm{~g}^{-1}$, respectively. The outer and inner specific surface areas of sepiolite are 8 and $250 \mathrm{~m}^{2} \mathrm{~g}^{-1}$, respectively. Therefore, the adsorption capacity of the outer surface of the sepiolite is negligible compared to that of the inner surface.

The sepiolite was ground gently in an agate mortar after drying at room temperature for 1 day. The obtained shapeless granular material was then separated into seven size fractions by dry sieving. The upper, lower and mean grain sizes of the fractions $(-r,+r$ and $r$, respectively) are listed in Table 1. Each fraction was stored in a plastic bottle with the lid closed tightly. The crystal structure, chemical composition, open porosity and adsorption capacity were the same in all of the size fractions. Only the fluid permeability changed depending on the mass, number, size and shape of the granules. The void volume distribution between the shapeless sepiolite granules was almost same as their particle-size distribution.

\section{Cigarettes}

Commercial cigarette samples $8 \mathrm{~mm}$ in diameter, $85 \mathrm{~mm}$ long and with $20 \mathrm{~mm}$ cellulose acetate filter tips were selected according to standards of the Cooperation Centre for Scientific Research Relative to Tobacco (CORESTA). Unfiltered cigarettes were prepared by carefully removing the filter tips. Various precursors were obtained by removing $5 \mathrm{~mm}$-long pieces from the middle of cellulose acetate matrix (Fig. 1). Modified filters were prepared by packing the sepiolite granules of a mean particle size into the void volume by a given amount. The prepared precursors include unfiltered (UF), cellulose acetate-filtered (CAF), precursor-filtered (PF) and sepiolite modified-filtered (SMF) cigarettes (Fig. 1). All cigarettes were kept at $22^{\circ} \mathrm{C}$ and $65 \%$ relative humidity for $48 \mathrm{~h}$ prior to machine smoking. 

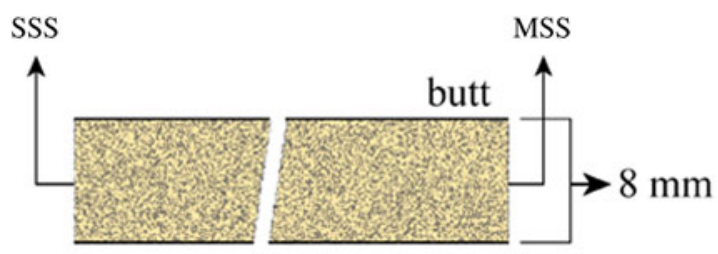

UF

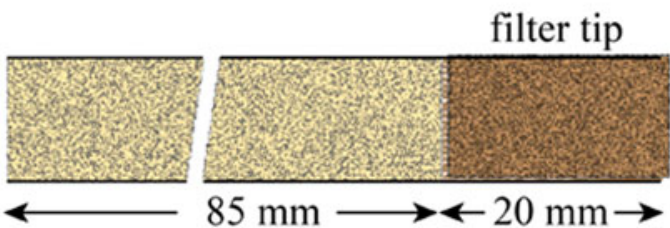

CAF
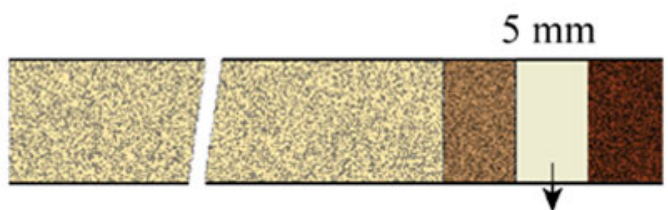

PF
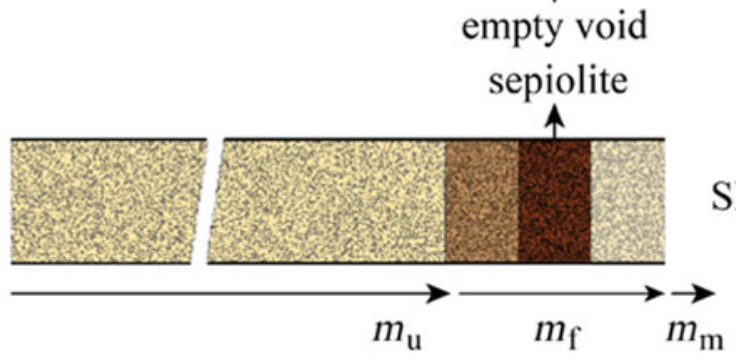

Fig. 1. Schematic representation of the UF, CAF, PF and SMF cigarettes.

\section{Machine smoking}

Five cigarettes for each sample (UF, CAF, PF and SMF) were smoked by using a Filtrona Model 302. A pad (Filtrona) $44 \mathrm{~mm}$ in diameter and $2 \mathrm{~mm}$ thick was used as a machine filter. During the smoking test, the parameters of the machine were set to run each experiment for $60 \mathrm{~s}$ with $2 \mathrm{~s}$ puff intervals, a puff volume of a $35 \mathrm{~mL}$ and a duration of $10 \mathrm{~s}$ between consecutive puffs. The butt lengths of the unfiltered and filtered cigarettes were kept at 8 and $28 \mathrm{~mm}$, respectively.

\section{Smoke condensate}

A heterogeneous mixture of water, nicotine and tar trapped on the machine filter is referred to as the crude-smoke condensate (CSC). The machine filter and its accessories were weighed before and after the smoking process. The difference between the two values obtained was taken as the mass of the CSC. The CSC was dissolved completely in $100 \mathrm{~mL}$ of methanol and the water was removed by selective adsorption on a dried synthetic zeolite 4A molecular sieve with high adsorption capacity. Nicotine and larger hydrocarbon molecules in the tar did not penetrate the $0.4 \mathrm{~nm}$-wide zeolite nanopores and remained in the solution. The water content in the CSC was considered equal to the mass increase of the zeolite $4 \mathrm{~A}$ due to adsorption. The difference between the masses of the CSC and water was then considered as the content of the dry-smoke condensate (DSC). The results were calculated as the mass of the CSC, water and DSC per cigarette filter.

\section{Nicotine and tar}

The anhydrous methanol solution contains nicotine and various types of organic molecules present in tar. This solution was mixed with a sufficient amount of water in a steam distillation flask. Alkaline nicotine was first converted into non-volatile sulfate salts by adding $5 \mathrm{~mL}$ of $1.00 \mathrm{M} \mathrm{H}_{2} \mathrm{SO}_{4}$ solution according to equation (1):

$$
2 \mathrm{C}_{10} \mathrm{H}_{14} \mathrm{~N}_{2}(a q)+\mathrm{H}_{2} \mathrm{SO}_{4}(a q) \rightarrow\left(\mathrm{C}_{10} \mathrm{H}_{14} \mathrm{~N}_{2} \mathrm{H}\right)_{2} \mathrm{SO}_{4}(s)
$$

The remaining volatile organic compounds originating from tar were then removed by steam distillation.

The nicotine sulfate salts remaining in the flask after steam distillation were again converted into nicotine molecules by adding $25 \mathrm{~mL}$ of $2.00 \mathrm{M} \mathrm{NaOH}$ solution according to equation (2):

$$
\begin{aligned}
& \left(\mathrm{C}_{10} \mathrm{H}_{14} \mathrm{~N}_{2} \mathrm{H}\right)_{2} \mathrm{SO}_{4}(s)+2 \mathrm{NaOH}(a q) \\
& \quad \rightarrow 2 \mathrm{C}_{10} \mathrm{H}_{14} \mathrm{~N}_{2}(a q)+\mathrm{Na}_{2} \mathrm{SO}_{4}(a q)+2 \mathrm{H}_{2} \mathrm{O}(l)
\end{aligned}
$$

Nicotine was purified by steam distillation. The nicotine content was determined with an ultraviolet-visible light (UV-VIS) spectrophotometer (Varian, Cary 50) at the wavelengths of maximum absorption (236, 259 and $282 \mathrm{~nm}$ ). The tar content was calculated as the difference between the masses of DSC and nicotine content. The masses of nicotine content and tar content retained in the machine filter from the MSS were calculated for each cigarette.

\section{Examination of used filter tips}

Scanning electron microscopy (SEM) and energy dispersive X-ray spectroscopy (EDX) analyses of the sepiolite samples before and after use as additives in the cigarette filter tips were obtained using a QUANTA 400F Field Emission SEM instrument operating at $30 \mathrm{kV}$. Prior to analysis, all samples were mounted on aluminium tape and coated with gold. The Fourier-transform infrared (FTIR) spectra of the raw and used sepiolite granules were obtained using a Spectrum 100 Perkin Elmer FTIR spectrometer. The FTIR spectra, in the range $400-4000 \mathrm{~cm}^{-1}$, were obtained using the attenuated total reflection sampling technique. For each sample, ten scans were recorded with a resolution of 10 $\mathrm{cm}^{-1}$. The XRD traces of the same samples were then recorded after preparation of oriented mounts following the glass slide method (Moore \& Reynolds, 1997) and using a Rigaku D-Max 2200 Powder Diffractometer with Ni-filtered $\mathrm{Cu}-\mathrm{K \alpha}$ radiation at $40 \mathrm{kV}$ and $30 \mathrm{~mA}$ and a scanning speed of $2^{\circ} 2 \theta \mathrm{min}^{-1}$.

\section{Results and discussion}

\section{Removal yields of the cigarette filters}

The mass balance of the condensate formed from the MSS per filtered cigarette can be written as follows:

$$
m_{\mathrm{u}}=m_{\mathrm{f}}+m_{\mathrm{m}}
$$

where $m_{\mathrm{u}}$ is the total mass, $m_{\mathrm{f}}$ is the mass removed by the cigarette filter and $m_{\mathrm{m}}$ is the trapped mass on the machine filter (Fig. 1). Thus, the mass balance for an unfiltered cigarette is as follows:

$$
m_{\mathrm{u}}=m_{\mathrm{m}}
$$


Table 2. Removal yields of tar and nicotine in the MSS by the UF, CAF and PF cigarettes.

\begin{tabular}{lccc}
\hline Cigarettes & UF & CAF & PF \\
\hline Tar & & & \\
$m_{\mathrm{u}}(\mathrm{mg})$ & 33.6 & - & - \\
$m_{\mathrm{m}}(\mathrm{mg})$ & 33.6 & 27.9 & 29.5 \\
$m_{\mathrm{f}}(\mathrm{mg})$ & 0 & 5.7 & 4.1 \\
$y$ & 0 & 0.17 & 0.12 \\
Nicotine & & - & - \\
$m_{\mathrm{u}}(\mathrm{mg})$ & 2.71 & 2.09 & 2.22 \\
$m_{\mathrm{m}}(\mathrm{mg})$ & 2.71 & 0.62 & 0.49 \\
$m_{\mathrm{f}}(\mathrm{mg})$ & 0 & 0.23 & 0.18 \\
$y$ & 0 & & \\
\hline
\end{tabular}

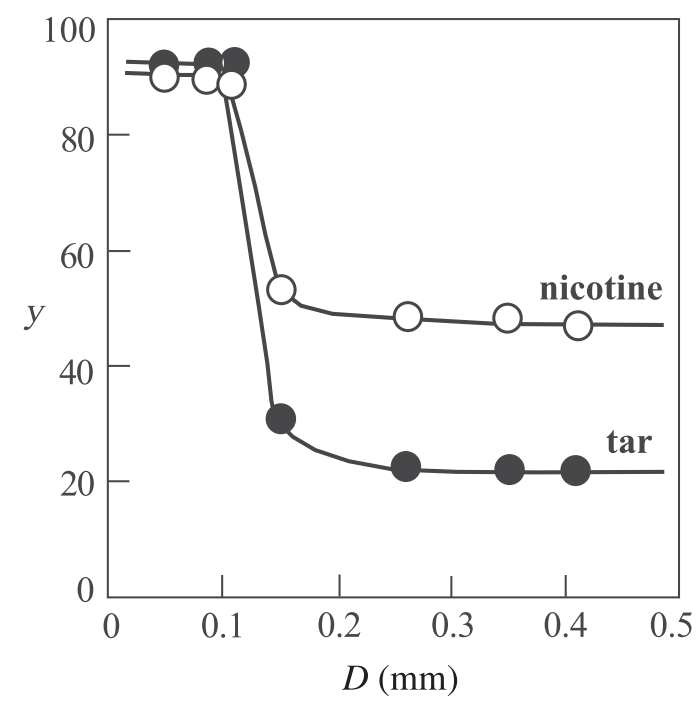

Fig. 2. The variation of the removal yields $(y)$ for tar and nicotine with respect to the granule size of sepiolite with a mass $\left(m_{\mathrm{s}}\right)$ of $95 \mathrm{mg}$.

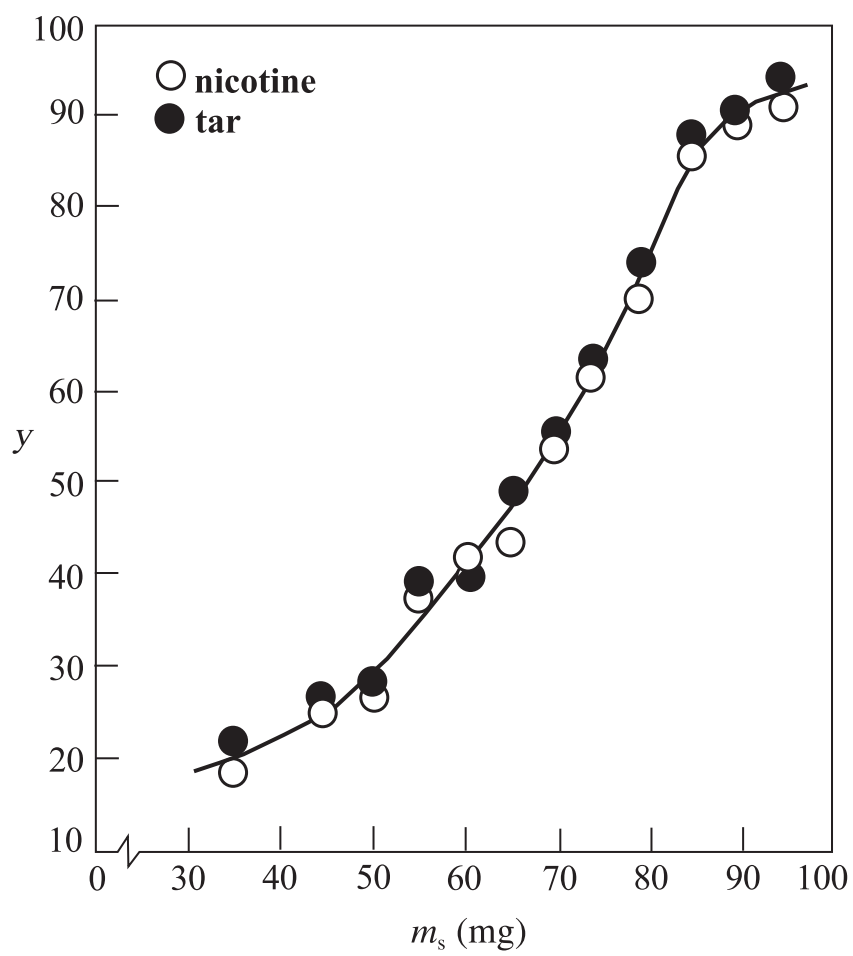

Fig. 3. The variation of the removal yields $(y)$ of tar and nicotine with respect to the mass of the sepiolite $\left(m_{\mathrm{s}}\right)$ of a mean granule size $(D)$ of $0.10 \mathrm{~mm}$.
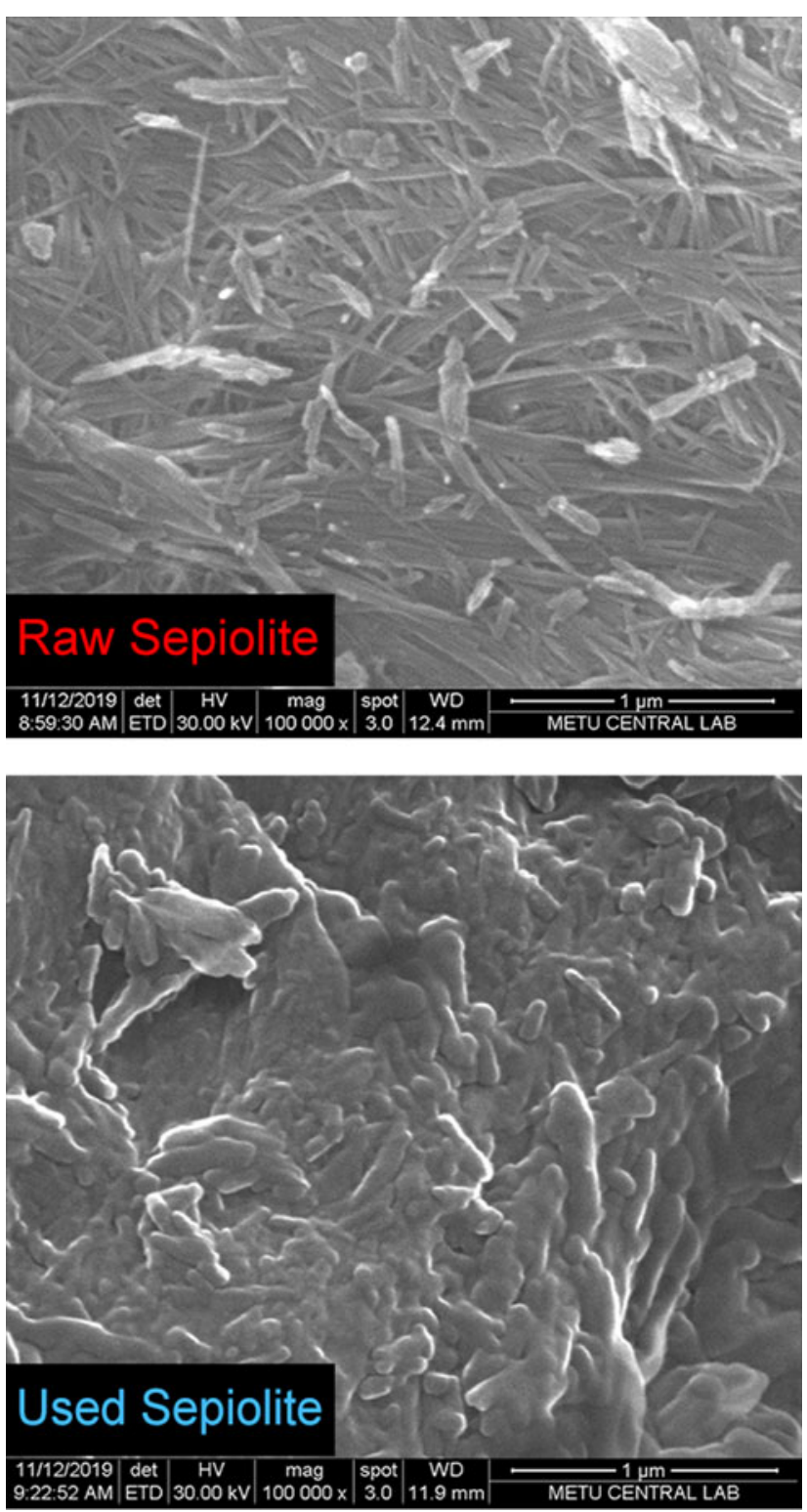

Fig. 4. SEM images of the sepiolite samples.

The yield $(y)$ of the condensate removed from the MSS using a filter tip is defined as follows:

$$
y=m_{\mathrm{f}} / m_{\mathrm{u}}
$$

The calculated masses and removal yield of tar and nicotine in the MSS with the CAF and PF cigarettes are given in Table 2.

\section{Relationship between the removal yield and particle size of sepiolite}

The SMF cigarettes (Fig. 1) smoked by the machine differ in the granule-size distribution of sepiolite. Accordingly, the process variable is mean particle size $(D)$. The variation in the removal yields $(y)$ of tar and nicotine as a function of $D$ for $95 \mathrm{mg}$ of sepiolite granules is shown in Fig. 2. The yields that are constant in the range of $0.15 \mathrm{~mm}<D<0.41 \mathrm{~mm}$ reached a maximum value at $D=0.10 \mathrm{~mm}$. The difference in removal yields for the given size interval of $D$ was due to the smaller nicotine content in the MSS 

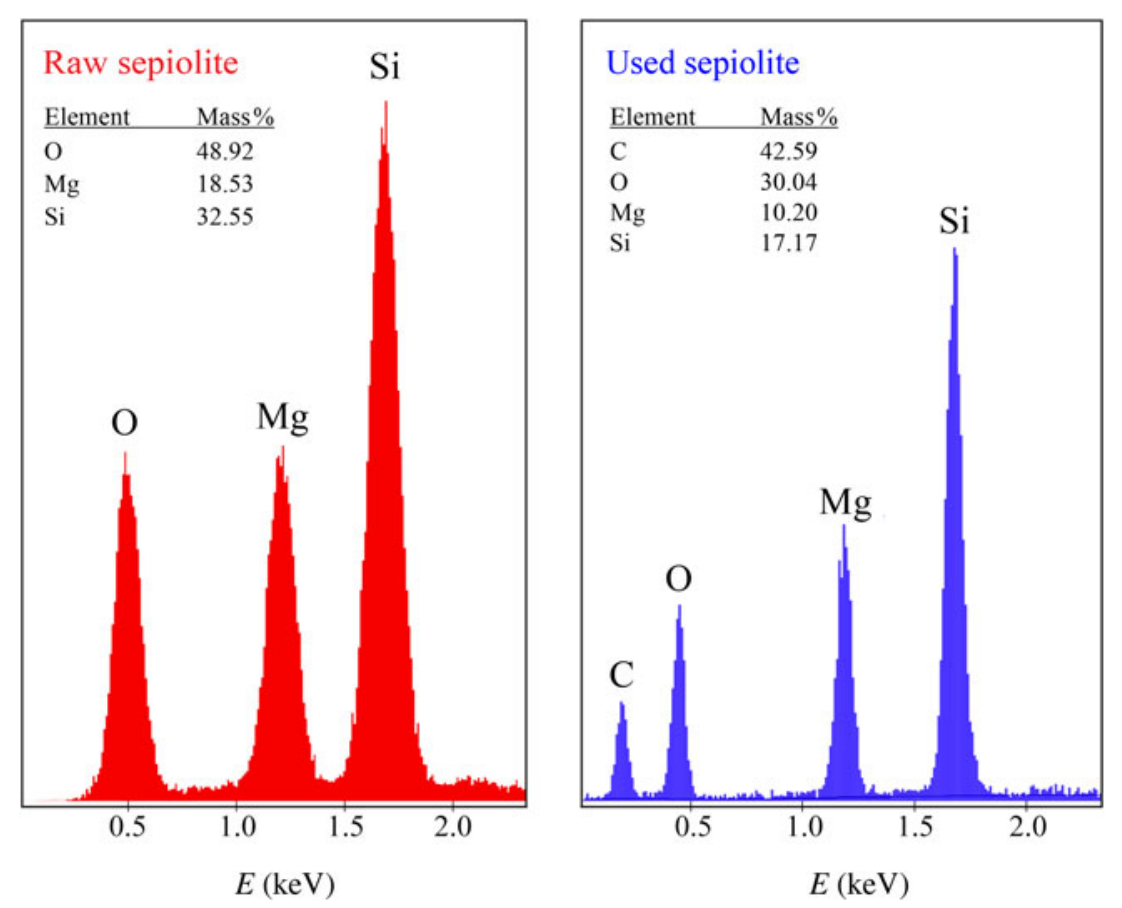

Fig. 5. EDX spectra of the sepiolite samples.

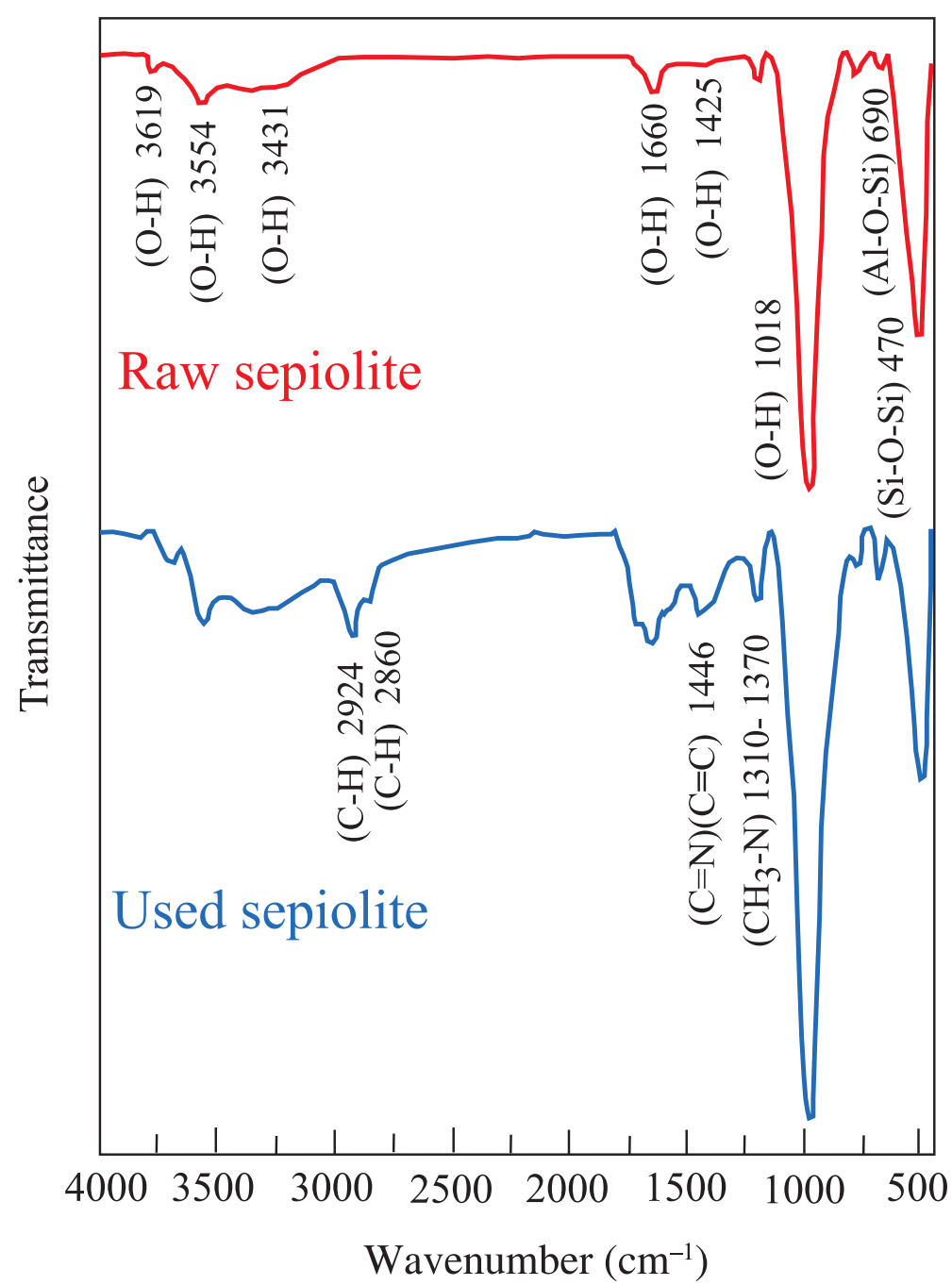

Fig. 6. FTIR spectra of the sepiolite samples. 
Fig. 7. XRD traces of the sepiolite samples. Sep = sepiolite; Dol = dolomite, according to Warr (2020).

compared to that of tar and partly to the dissolution of nicotine in the zeolitic water. The condensation increased at $D<0.10 \mathrm{~mm}$ due to the decrease in the permeability of larger organic molecules among the fibre clusters of sepiolite. Consequently, cellulose acetate cigarette filter can be modified to obtain a desirable removal yield for tar and nicotine by changing the mass of the sepiolite granules with $D=0.10 \mathrm{~mm}$.

\section{Relationship between the removal yield and mass of sepiolite}

The SMF cigarettes (Fig. 1) smoked by the machine are similar except for the mass of sepiolite. Accordingly, the variable of the process is the mass of the sepiolite granules with a similar particle-size distribution. The variation in the removal yields ( $y$ ) of tar and nicotine with respect to the mass of the sepiolite granules with a $D$ of $0.10 \mathrm{~mm}$ is given in Fig. 3. Despite the different masses of tar and nicotine retained per cigarette filter, the corresponding removal yields were almost equal in both cases. The yields increased gradually with the increasing mass of sepiolite granules of $D=0.10 \mathrm{~mm}$, showing a smooth curve. Thus, filter tips with the desired removal yields for tar and nicotine can be prepared by modifying the cellulose acetate filter using sepiolite granules with definite mean particle sizes and masses.

\section{Interaction between sepiolite and cigarette smoke}

The removal yields of sepiolite granules at the same mass depend on the size distribution. In addition, they depend on the number of the granules having different masses but similar size distributions. The condensation amount increases with both the size and mass of the granules, whereas the adsorbed amount is affected only by the mass and not by the size of the granules. Hence, the removal of tar and nicotine by the sepiolite granules is due to condensation rather than adsorption. Condensation occurs during the MSS flow through the stationary bed of rough sepiolite granules of different sizes, shapes and numbers that are randomly compacted. The flow rate decreases with the increasing number of collisions amongst the large organic molecules and the granules. Hence, the friction during the MSS flow through the bed of sepiolite granules increased the retention time and trapped the condensate.

The SEM images show the fibre cluster structure of sepiolite granules and the condensation of large molecules in the tar and nicotine on the fibres of the clusters (Fig. 4). The EDX spectra of the raw and used sepiolite samples are shown in Fig. 5. The excess amount of carbon in the used samples shows that the accumulation on the sepiolite bed is due to condensation rather than adsorption. The remaining gaseous mixture flows through the voids between the granules. The FTIR bands on the spectrum of raw sepiolite (Perraki \& Orfanudaki, 2008) and used sepiolite (Fig. 6) are also in agreement with the SEM images. The stretching bands for $\mathrm{C}-\mathrm{H}, \mathrm{C}=\mathrm{C}, \mathrm{C}=\mathrm{N}$ and $\mathrm{CH}_{3}-\mathrm{N}$ indicate that the tar and nicotine were mainly condensed on the sepiolite fibres after multimolecular adsorption. According to the XRD traces, the smoke does not affect the crystal structure of the sepiolite (Fig. 7). 


\section{Conclusions}

The air-dried sepiolite granules with zeolitic water were effective additives in cellulose acetate filter tips for the removal of tar and nicotine from the MSS of cigarette. The removal yields for tar and nicotine were strictly dependent on the mean sizes and masses of the sepiolite granules. Therefore, various filter tips with desired removal yields can be prepared by modifying either of these parameters. Organic molecules in the MSS are retained on the fibres of the cluster structure of sepiolite granules rather than in the voids between them. However, a portion of the nicotine dissolves in the water existing in the pores of the sepiolite fibres. The crystal structure of sepiolite is not affected by the smoking process.

Financial support. Support for this work was provided by the Scientific and Technological Research Council of Turkey (TBAG-576/C) and Ankara University Research Fund (12B4240016).

\section{References}

Abtahi A. (1985) Synthesis of sepiolite at room temperature from $\mathrm{SiO}_{2}$ and $\mathrm{MgCl}_{2}$ solution. Clay Minerals, 20, 521-523.

Ahlrichs J.L., Serna C. \& Serratosa J.M. (1975) Structural hydroxyls in sepiolites. Clays and Clay Minerals, 23, 119-124.

Al-Ani A., Gertisser, R. \& Zholobenko, V. (2018) Structural features and stability of Spanish sepiolite as a potential catalyst. Applied Clay Science, 162, 297-304.

Artho A., Beringer M., Buchman, P. \& Koch R. (1976) Smokable Product with Meerschaum Particles. Unites States Patent 3987800A.

Balc1 S. (1999) Effect of heating and pre-treatment on pore size distribution of sepiolite. Clay Minerals, 34, 647-655.

Bergaya F., Theng B.K.G. \& Lagaly G. (editors) (2006) Handbook of Clay Science. Elsevier, Amsterdam, The Netherlands, 1246 pp.

Bonilla J.L., Lopez-Gonzales J.D.D., Ramirez-Saens A., Rodriguez-Reinoso F. \& Valenzuela-Calahorro C. (1981) Activation of a sepiolite with dilute solutions of $\mathrm{HNO}_{3}$, and subsequent heat treatment: II. Determination of surface acid centers. Clay Minerals, 16, 173-179.

Brauner K. \& Preisinger A. (1959) Structur und entstehung des sepioliths. Tschermaks Mineralogische und Petrographische Mitteilungen, 6, 120-140.

Çetişli H. \& Gedikbey T. (1990) Dissolution, kinetics of sepiolite from Eskişehir (Turkey) in hydrochloric and nitric acids. Clay Minerals, 25, 207-215.

Chen Z., Zhang L., Tang Y. \& Jia Z. (2006) Adsorption of nicotine and tar from the mainstream smoke of cigarettes by oxidized carbon nanotubes. Applied Surface Science, 252, 2933-2937.

Coggins C.R.E. \& Gaworski C.L. (2008) Could charcoal filtration of cigarette smoke reduce smoking-induced disease? A review of the literature. Regulatory Toxicology and Pharmacology, 50, 359-365.

Corma A., Perez-Pariente J., Fornes V. \& Misfud A. (1984) Surface acidity and catalytic activity of a modified sepiolite. Clay Minerals, 19, 673-676.

Counts M.E., Morton M.J., Laffoon S.W., Cox R.H. \& Lipowicz, P.J. (2005) Smoke composition and predicting relationship for international commercial cigarettes smoked with three machine-smoking conditions. Regulatory Toxicology and Pharmacology, 41, 185-227.

Ece Ö.I. \& Çoban F. (1994) Geology, occurrence, and genesis of Eskişehir sepiolites, Turkey. Clays and Clay Minerals, 42, 81-92.

Erdoğan B., Demirci Ş. \& Akay Y. (1996) Treatment of sugar, beet juice white bentonite, sepiolite, diatomite, and quartamin to remove color and turbidity. Applied Clay Science, 11, 55-67.

Figlar J.N., Tucker B.E. \& St. Charles K. (2004) Cigarette Filter. United States Patent 6779529B2.

Fitaroni L.B., Venâncio T., Tanaka F.H., Gimenez J.C.F., Costa J.A.S. \& Cruz S.A. (2019) Organically modified sepiolite: thermal treatment and chemical and morphological properties. Applied Clay Science, 179, 1-10.

Frost R.L. \& Ding Z. (2003) Controlled rate thermal analysis and differential scanning calorimetry of sepiolites and palygorskites. Thermochimica Acta, 397, $119-128$.

Galan E. (1996) Properties and applications of palygorskite-sepiolite clays. Clay Minerals, 31, 443-453.
Gao L., Cao Y., Zhou S.L., Zhuang T.T., Wang Y. \& Zhu, J.H. (2009) Eliminating carcinogenic pollutants in environment: reducing the tobacco specific nitrosamines level of smoke by zeolite-like calcosilicate. Journal of Hazardous Materials, 169, 1034-1039.

Göktaş A.A., Mısırlı Z. \& Baykara T. (1997) Sintering behavior of sepiolite. Ceramics International, 23, 305-311.

González-Santamaria, D.E., Lopez E., Ruiz A., Fernández R., Ortega A. \& Cuevas, J. (2017) Adsorption of phenanthrene by stevensite and sepiolite. Clay Minerals, 52, 341-350.

Inukai K., Miyawaki R., Tomura S., Shimosaka K. \& Irkeç T. (1994) Purification of Turkish sepiolite through hydrochloric acid treatments. Applied Clay Science, 9, 11-29.

Jimenez-Lopez J., Lopez-Gonzalez J.D., Ramirez-Saenz A., Rodriguez-Reinoso F., Valenzuela-Calahorro C. \& Zurita-Herrera L. (1978) Evolution of surface area in a sepiolite as a function of acid and heat treatments. Clay Minerals, 13, 375-385.

Kim K.-H., Kabir E. \& Jahan S.A. (2016) Waterpipe tobacco smoking and its human health impacts. Journal of Hazardous Materials, 317, 229-236.

Kiyohiro T. \& Otsuka R. (1989) Dehydration mechanism of bound water in sepiolite. Thermochimica Acta, 147, 127-138.

Ködderitzsch P., Bischoff R., Veitenhansl P., Lorenz W. \& Bischoff, G. (2005) Sensor array based measurement technique for fast-responding cigarette smoke analysis. Sensors and Actuators B: Chemical, 107, 479-489.

Kulbicki G. (1959) High temperature phases in sepiolite, attapulgite and saponite. American Mineralogist, 44, 752-758.

Laatikainen M., Srithammavut W., Toukoniitty B., Turunen I. \& Sainio T. (2015) Phospholipid adsorption from vegetable oils on acid-activated sepiolite. Adsorption, 21, 409-417.

Lamb C.G. \& Parenski H.S. (1984) Cigarette Filter. United States Patent 4457319.

Li G., Yu H., Xu L., Ma Q., Chen C., Hao Q. \& Qian Y. (2011) General synthesis of carbon nanocages and their adsorption of toxic compounds from cigarette smoke. Royal Society of Chemistry, 3, 3251-3257.

Meşe E., Figen A.K., Filiz B.C. \& Pişkin S. (2018) Cobalt-boron loaded thermal activated Turkish sepiolite composites (Co-B@tSe) as a catalyst for hydrogen delivery. Applied Clay Science, 153, 95-106.

Mirzaaghaei M., Goli S.A.H. \& Fathi G. (2017) Clarification of apple juice using activated sepiolite as a new fining clay. Clay Minerals, 52, 497-508.

Moore D.M. \& Reynolds R.C. Jr (1997) X-ray diffraction and the identification and analysis of clay minerals. Oxford University Press, Oxford, UK, 400 pp.

Murray H.H. (1999) Applied clay mineralogy today and tomorrow. Clay Minerals, 34, 39-49.

Ogorodova L.P., Kiseleva I.A., Vigasina M.F., Kabalov Y.K., Grishchenko R.O. \& Mel'chakova L.V. (2014) Natural sepiolite: enthalpies of dehydration, dehydroxylation, and formation derived from thermochemical studies. American Mineralogist, 99, 2369-2373.

Önal M., Yılmaz H. \& Sarkkaya Y. (2008) Some physicochemical properties of the white sepiolite known as pipestone from Eskișehir, Turkey. Clays and Clay Minerals, 56, 511-519.

Özdemir M. \& Kıpçak İ. (2004) Dissolution kinetics of sepiolite in hydrochloric acid and nitric acid. Clays and Clay Minerals, 52, 714-720.

Panday S.K. \& Kim K.H. (2010) A review of environmental tobacco smoke and its determination in air. Trends in Analytical Chemistry, 29, 804-819.

Papoulis D., Somalakidi K., Todorova N., Trapalis C., Panagiotaras D., Sygkridou D. et al. (2019) Sepiolite/ $\mathrm{TiO}_{2}$ and metal ion modified sepiolite/ $\mathrm{TiO}_{2}$ nanocomposites: synthesis, characterization and photocatalytic activity in abatement of $\mathrm{NO}_{\mathrm{x}}$ gases. Applied Clay Science, 179, 1-6.

Perraki T. \& Orfanoudaki A. (2008) Study of raw and thermally treated sepiolite from the Mantoudi area, Euboea, Greece: X-ray diffraction, TG/DTG/DTA and FTIR investigations. Journal of Thermal Analysis and Calorimetry, 91, 589-593.

Pinto E., Cruz M., Ramos P., Santos A. \& Almeida A. (2017) Metals transfer from tobacco to cigarette smoke: evidences in smokers' lung tissue. Journal of Hazardous Materials, 325, 31-35.

Prost R. (1975) Infrared study of the interactions between the different kinds of water molecules present in sepiolite. Spectrochimica Acta, 31A, 1497-1499.

Purkis S.W., Cahours X., Rey M., Teillet B., Troude V. \& Verron T. (2011) Some consequences of using cigarette machine smoking regimes with 
different intensities on smoke yields and their variability. Regulatory Toxicology and Pharmacology, 59, 293-309.

Rodriguez-Reinoso F., Ramirez-Saenz A., Lopez-Gonzalez J.D.D., ValenzuelaCalahorro C. \& Zurita-Herrera L. (1981) Activation of sepiolite with dilute solutions of $\mathrm{HNO}_{3}$ subsequent heat treatment: III. Development of porosity. Clay Minerals, 16, 315-323.

Rouquerol F., Rouquerol J., Sing K.S.W., Llewellyn P. \& Maurin G. (2014) Adsorption by Powders and Porous Solids, 2nd ed. Elsevier, Amsterdam, The Netherlands, $646 \mathrm{pp}$.

Rustemeier K., Stabbert R., Haussmann H.J., Roemer E. \& Carmines E.L. (2002) Evaluation of the potential effect of ingredients added to cigarettes. Part 2: chemical composition of mainstream smoke. Food and Chemical Toxicology, 40, 93-104.

Saneei M., Goli S.A.H. \& Keramat J. (2015) Optimization of oil bleaching parameters using response surface methodology, for acid-activated sepiolite from Iran. Clay Minerals, 50, 639-648.

Sarıkaya Y., Önal M. \& Pekdemir A.D. (2020a) Kinetic and thermodynamic approaches on thermal degradation of sepiolite crystal using XRD-analysis. Journal of Thermal Analysis and Calorimetry, 140, 2667-2672.

Sarıkaya Y., Önal M. \& Pekdemir A.D. (2020b) Thermal degradation kinetics of sepiolite. Clay Minerals, 55, 96-100.

Sasaki T., Matsumoto A. \& Yamashita Y. (2008) The effect of the pore size and volume of activated carbon on adsorption efficiency of vapor phase compounds in cigarette smoke. Colloids and Surfaces A: Physicochemical and Engineering Aspects, 325, 166-172.

Serna C., Ahlrichs J.L. \& Serratosa J.M. (1975) Folding in sepiolite crystals. Clays and Clay Minerals, 23, 452-457.

Shuali U., Yariv S., Steinberg M. \& Müller-Vanmoos M. (1991) Thermal analysis of pyridine-treated sepiolite and palygorskite. Clay Minerals, 26, 497-506.

Smith C.J., Livingston S.D. \& Doolittle, D.J. (1997) An international literature survey of 'IARC group I carcinogens' reported in mainstream cigarette smoke. Food and Chemical Toxicology, 35, 1107-1130.

Thielen A., Klus H. \& Müller L. (2008) Tobacco smoke: unraveling a controversial subject. Experimental and Toxicologic Pathology, 60, 141-156.
Tian B.Z., Chen P., Chen J. \& Bai, L. (2009) Blocking and filtering effect of Bombyx mori silkworm silk fiber filter tips against mainstream smoke of cigarettes. Materials \& Design, 30, 2289-2294.

Tian G., Han G., Wang F. \& Liang J. (2019) Sepiolite nanomaterials: structure, properties and functional applications. Pp. 135-201 in: Nanomaterials from Clay Minerals (A. Wang \& W. Wang, editors). Elsevier, Amsterdam, The Netherlands.

Tian G., Wang W., Kang Y. \& Wang A. (2014) Study on thermal activated sepiolite for enhancing decoloration of crude palm oil. Journal of Thermal Analysis and Calorimetry, 117, 1211-1219.

Verdolotti L., Salerno A., Lamanna R., Nunziata A., Netti P. \& Iannace S. (2012) A novel hybrid PU-alumina flexible foam with superior hydrophilicity and adsorption of carcinogenic compounds from tobacco smoke. Microporous and Mesoporous Materials, 151, 79-87.

Wang F., Liang J., Tang Q., Chen C. \& Chen, Y. (2014) Channel microstructure and thermal insulation mechanism of sepiolite mineral nanofibers. Journal of Nanoscience and Nanotechnology, 14, 3937-3942.

Warr L.N. (2020) Recommended abbreviations for the names of clay minerals and associated phases. Clay Minerals, 55, 261-264.

Xu Y., Zhu J.H., Ma L.L., Ji A., Wei Y.L. \& Shang X.Y. (2003) Removing nitrosamines from mainstream smoke of cigarettes by zeolites. Microporous and Mesoporous Materials, 60, 125-138.

Yebra-Rodriguez A., Martin-Ramos J.D., Del Rey F., Viseras C. \& Lopez-Galindo A. (2003) Effect of acid treatment on the structure of sepiolite. Clay Minerals, 38, 353-360.

Yener N., Önal M., Üstünışık G. \& Sarıkaya Y. (2007) Thermal behavior of a mineral mixture of sepiolite and dolomite. Journal of Thermal Analysis and Calorimetry, 88, 813-817.

Yılmaz M.S., Kalpaklı Y. \& Pişkin S. (2013) Thermal behavior and dehydroxylation kinetics of naturally occurring sepiolite and bentonite. Journal of Thermal Analysis and Calorimetry, 114, 1191-1199.

Zhang G.K. (2000) Development of sepiolite type filter tips of cigarette. Journal of Wuhan University of Technology - Materials Science Edition, 15, 4779-4786. 